\title{
RECOGNITION AND PRODUCTIVITY AMONG AMERICAN POLITICAL SCIENGE DEPARTMENTS
}

\author{
David R. Morgan, University of Oklahoma \\ and \\ Mrchael R. Frtzgerald, University of Missouri, Columbia
}

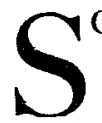

OCIAL SCIENTISTS have displayed only a limited interest in science as a system of knowledge and behavior, and what analysis has been done focuses primarily on the work of natural scientists. ${ }^{1}$ In recent years, however, sociologists have begun to study systematically the process of discovery and dissemination of knowledge within their particular discipline. Political scientists, on the other hand, have not been especially self-conscious about the nature of their professional activities. As a past president of the American Political Science Association remarked in his 1971 presidential address, "it is surprising how little we know about ourselves." In particular, while some attention has been devoted to exploring the parameters of productivity and creativity in other scientific disciplines, almost no serious analyses of these important dimensions of the discipline of political science have been undertaken. The purpose of this brief report is to contribute to the process of understanding the nature of productivity and recognition among departments of political science in this country. Specifically, we offer a measure of productivity, rank departments on this measure, determine how these rankings compare with measures of quality, and finally, report the results of an effort to account for variation among political science departments on the measure of productivity.

Assessments of the output of individual scientists and of the university departments with which they are affiliated have taken several forms, but most research of this type has concentrated on the nature of individual scholarly activity with the purpose of determining such things as the variation in productivity and recognition among scientists at major and minor universities, ${ }^{3}$ patterns of collaboration in authorship, ${ }^{4}$ or even questions of name ordering among authors of scientific papers. ${ }^{5}$ Several interesting findings emerge from such efforts. Typologies are offered suggesting that scientists can be categorized as "prolific" (frequent publication and many citations), "mass producers" (frequent publication with few citations), "perfectionists" (infrequent publication but many citations), and "silents" (infrequent publication and citation) .6 Perfectionists among natural scientists were found to be most likely to receive recognition in the form of affiliation with the most dis-

${ }^{1}$ Barney G. Glaser, Organizational Scientists: Their Professional Careers (Indianapolis: Bobbs-Merrill, 1964); Warren O. Hagstrom, The Scientific Community (New York: Basic Books, 1965); Norman W. Storer, The Social System of Science (New York: Holt, Rinehart, and Winston, 1966); Janice Lodahl and Gerald Gordon "The Structure of Scientific Fields and the Functioning of University Graduate Departments," American Sociological Review 37 (February 1972) : 57-72; Jonathan Cole and Stephen Cole, Social Stratification in Science (Chicago: University of Chicago Press, 1973) ; and Warren O. Hagstrom, "Competition in Science," American Sociological Review 39 (February 1974): 1-18.

${ }^{2}$ Robert E. Lane, "To Nurture a Discipline," American Political Science Review 66 (March 1972): 166.

${ }^{3}$ Diana Crain, "Scientists at Major and Minor Universities: A Study of Productivity and Recognition," American Sociological Review 30 (October 1965) : 699-713.

"Harriet Zuckerman, "Nobel Laureates in Science: Patterns of Productivity, Collaboration, and Authorship," American Sociological Review 32 (June 1967) : 391-403.

"Harriet Zuckerman, "Patterns of Name Ordering Among Authors of Scientific Papers: A Study of Social Symbolism and Its Ambiguity," American Journal of Sociology 74 (November 1968): 276-91.

"Stephen Cole and Jonathan Cole, "Scientific Output and Recognition: A Study in the Operation of the Reward System in Science," American Sociological Review 32 (June 1967): 377-90. 
tinguished departments. Several studies also indicate that a cumulative reputational advantage accrues to those scientists who receive early recognition as opposed to those who do not become known in the formative stages of their professional careers. Merton describes this as the "Matthew Effect," taking from the Gospel of the same name the adage, "For unto everyone that hath be given, and he shall have abundance: But from him hath not shall be taken away...." Merton actually identifies this occurrence as a "complex pattern of the misallocation of credit for scientific work...."7 An apparent advantage with respect to professional recognition also lies with those scientists at major as opposed to minor schools. ${ }^{8}$ The self-perpetuating nature of scholarly advancement and acknowledgment is further documented by studies revealing that scientists elected to membership in the highly prestigious National Academy of Sciences come from a relatively small number of universities. In fact over 90 percent of the doctoral degrees from American Universities $(N=710)$ that were awarded to these eminent scholars came from just twenty schools. ${ }^{9}$ In sum, it appears that among natural scientists, achievement and recognition are often associated with major university affiliation, early publication, and a doctorate from a prestigious university.

Any attempt to explore the dimensions of scientific enterprise inevitably confronts the problem of how to operationalize such concepts as creativity, productivity, and quality. Quantitative output by individual scholars is clearly easiest to measure - books, articles, and papers may be counted. Quality of research is not so readily agreed upon. The number of citations to an individual's work is the most frequent method of evaluating the quality of scholarship among natural scientists. ${ }^{10}$ The assessment of an entire department on this basis, however, would be quite a timeconsuming and difficult task. For this reason the periodic reputationally based ratings published under the auspices of the American Council on Education are commonly employed to gauge the quality of academic departments both in the natural sciences and in other disciplines. In spite of the problems associated with adequately measuring quality, Cole and Cole found that among American physicists, "Quality of output is more significant than quantity in eliciting recognition through the receipt of awards, appointment to prestigious academic departments, and being widely known to one's colleagues."11

In the social sciences, sociologists have taken the lead in examining questions of productivity and recognition within their discipline. Certain similarities can be noted in the results of this effort when compared with the findings among natural scientists. Among sociologists, "prolific" scholars (high quality plus quantity) were most often associated with prestigious departments, ${ }^{12}$ unlike the situation prevailing among natural scientists. Tendencies toward high or low publication productivity is generally established fairly early in the career of the social scientist, ${ }^{13}$ although no evidence has been forthcoming to this point to confirm or disconfirm the presence of a "Matthew effect" among this group of scholars. Nonetheless, among political scientists, prolific journal article publishers are also quite likely to

\footnotetext{
'Robert K. Merton, "The Matthew Effect in Science," Science 159 (January 1968) : $56-63$ Also see Paul D. Allison and Jack Stewart, "Productivity Differences Among Scientists: Evidence for Accumulative Advantage," American Sociological Revieze 39 (August 1974) : 596-606.

${ }^{8}$ Crane, "Scientists at Major and Minor Universities."

${ }^{9}$ Don E. Kash et al., "University Affiliation and Recognition: National Academy of Sciences," Science 175 (March 1972) : 1076-84.

"Cole and Cole, "Scientific Output and Recognition."

12 Ibid.

E. Timothy Lightfield, "Output and Recognition of Sociologists," American Sociologist 6 (May 1971): 128-33.

${ }^{13}$ Jerome Mathis, "Some Academic Influences upon Publication Productivity," Social Forces 29 (March 1951): 267-72.
} 
have at least one book or monograph; in fact, 47 percent of those with eleven to twenty or more articles have written five or more books. A strong relationship was also found between number of articles published and prestige graduate training. ${ }^{14}$

Judging the quality of academic output among practitioners of social science is even more vexing than evaluating the work of natural scientists. This stems principally from a basic difference between physical and social sciences in the degree to which consensus is found for a dominant paradigm. Logically, the more agreement that exists on the appropriate scientific paradigm, the more likely a discipline can advance its knowledge in an orderly, consistent, cumulative fashion. Commonly this requires reliance on the medium of papers, articles, and similar exchanges among interested scholars. In such instances, the task is not global but incremental, requiring that each new piece of knowledge be presented in such a way that its contribution can be gauged by other practitioners. While Kuhn describes this process as "normal" science, ${ }^{15}$ it nonetheless involves a creative process in the conventional usage of the term. As Merton suggests, ". . in the institution of science originality is at a premium. For it is through originality, in greater or smaller increments that knowledge advances...."16 The social sciences obviously lack such widely shared paradigms, and partly for this reason, some contend that the publication of research and theoretical monographs represents the most significant scholarly achievement for these disciplines. A recent survey confirms this belief among sociologists. ${ }^{17}$ If one accepts this position, however, assessing productivity - either quantitatively or qualitatively - becomes extraordinarily difficult for two reasons. First, nothing comparable to the Science Citation Index existed for the social sciences until 1973 when the Social Science Citation Index began publication. This makes it virtually impossible to conduct longitudinal research using citations as measures of quality. Second, if quantity of output is the focus, locating the books published by particular scholars during a given period would exhaust the resources of all but the best financed research team. On theoretical grounds, moreover, an argument can be made that as a social science discipline strives to become more scientific, the norms employed in the hard sciences for evaluating scholarly attainment are more applicable. Originality becomes the essential touchstone for judging the worth of a scientific contribution. While the research monograph may offer new contributions both theoretically and empirically, the peer review process associated with the publication in scholarly periodicals is probably the best means available for assuring that published research meets standards which apply disciplinewide. Thus, for practical and theoretical reasons the index of productivity developed below is based upon journal article publication.

\section{Methodology}

No single operationalization of scientific productivity will satisfy everyone. Inevitably, matters of judgment and preference intrude so as to compound the difficulty of a task already constrained by data limitations. Therefore, at the outset we acknowledge that the measure to be developed below is a crude representation of the professional productivity of selected political science departments.

Initially, a decision had to be made regarding a time pararneter. Although subjective evaluations of departmental stature undoubtedly change slowly, actual

\footnotetext{
${ }^{14}$ Charles D. Hadley, "Teaching Political Scientists: The Gentrality of Research," PS 5 (Summer 1972): 262-70.

${ }^{15}$ Thomas S. Kuhn, The Structure of Scientific Revolutions, 2d ed. (Ghicago: University of Chicago Press, 1970).

${ }^{16}$ Robert K. Merton, "Priorities in Scientific Discovery: A Chapter in the Sociology of Science," American Sociological Review 22 (December 1957): 639.

${ }^{17}$ Norval Glenn and Wayne Villemez, "The Productivity of Sociologists at 45 American Universities," American Sociologist 5 (August 1970): 244-52.
} 
productivity rates may vary somewhat over time. We assumed that any period longer than ten years would not adequately reflect current levels of output, and so the period selected for this analysis is 1964-73.

A second basic decision concerned the number and identity of the professional journals to be included in an index of productivity. A recent survey by Giles and Wright $^{18}$ of political scientists' evaluation of the relative merits of the discipline's learned journals included a total of sixty-three such publications. Not only would analyzing that large a number seem prohibitive, such an exhaustive list may not be reflective of the general balance of fields and specialties within the discipline. To include all might bias the index in favor of those departments which have particularly prominent specializations. For these reasons the measure of productivity to follow is based on articles published in the principal journal of the discipline, the American Political Science Review, and the four regional, general-purpose journals: The Journal of Politics; the American Journal of Political Science (until 1973, the Midwest Journal of Political Science); Polity; and the Western Political Quarterly. Articles and research notes were counted equally, but less independent contributions such as rejoinders, replies, or comments were omitted. ${ }^{19}$ Selections from the various journals were not weighted equally in the index since it was our initial impression that this would not reflect commonly felt distinctions among the five periodicals. Fortunately, we did not have to apply our own weighting formula but instead were able to rely on the rankings of a randomly selected sample of political scientists $(N=255)$ surveyed by Giles and Wright. This 1974 evaluation produced the following ratings on a zero (poor) to ten (outstanding) scale with the values shown in parenthesis when the APSR is equal to one: ${ }^{20}$

$\begin{array}{llr}\text { APSR } & 7.0 & (1.000) \\ \text { JOP } & 6.7 & (.957) \\ \text { AJPS } & 6.6 & (.943) \\ \text { Polity } & 5.9 & (.843) \\ \text { WPQ } & 5.8 & (.829)\end{array}$

Multiple authorships were counted so that no single article had a value of more than one.

The scheme outlined above probably discriminates against certain members of the discipline and consequently may affect the rankings of certain departments. In particular, scholars outside the field of American politics are probably underrepresented in such an index. For the period 1960-70, Walker's examination of the same five journals found that the subjects of political parties, public opinion, and elections and voting accounted for 36 percent of the journal space while world politics and political development represented only 10 percent. ${ }^{21}$ Some of the articles in the first group surely were cross-national in nature, but the clear impression remains that American politics scholars fare better than others in the pages of the five journals under consideration. Also, it might be noted that World Politics,

${ }^{18}$ Micheal W. Giles and Gerald C. Wright, Jr., "Political Scientists' Evaluations of Sixty-three Journals," PS 8 (Summer 1975) : 254-56. This survey was mailed to a random sample of 515 members of the American Political Science Association in April 1974 (excluding graduate students and members not listed as affiliated with a $\mathrm{Ph}$.D. granting institution) and to a supplemental sample of 115 chairmen of these same departments. The return rate was approximately 50 percent. The authors express surprise that the $A P S R$ was not the top-ranked journal and suggest that its third place position results from " . . a rather discontented faction of the discipline giving it very low ratings (... the $A P S R$ has the largest standard deviation)...."P. 254.

${ }^{18}$ No attempt was made to identify those authors professing disciplines other than political science because of the obvious difficulty in making such a determination. This undoubtedly produces some bias in the resulting productivity index but of a random nature, we hope.

${ }^{20}$ Giles and Wright, "Political Scientists' Evaluations," pp. 255-56.

${ }^{21}$ Jack L. Walker, "Brother Can You Paradigm," PS 5 (Fall 1972) : 419-22. 
which had a slightly higher overall ranking in the survey than the $A P S R$, obviously represents a most attractive alternative outlet for certain scholars. This might mean that such specialists would have a lower publication rate in the five general journals. Nonetheless, while one might wish to include a few specialized journals, it becomes virtually impossible to know where to draw the line. ${ }^{22}$

\section{The Results}

Table 1 displays the rankings of the fifty top institutions along with the number of articles published in each journal and the overall weighted productivity index. ${ }^{23}$ It might be mentioned here that the top ten departments accounted for about 21 percent of the total number of articles published in the five journals for 1964-73. The highest twenty schools were responsible for 34 percent of all articles while the fifty leading departments published 55 percent of the total. Thus as one goes from the most prolific departments (e.g., top ten) downward, the faculties from the lower ranked schools contributed disproportionately less to the total journal output for this period.

Several interesting results can be observed from Table 1, especially if one focuses on the highest rankings. Two schools, Kentucky and Georgia, that are not normally regarded as being in the same category with the most prestigious departments are ahead of many of their better-known rivals. Likewise, several departments traditionally considered highly distinguished do not fare as well as might be expected. As a more meaningful basis for this comparison, Table 2 presents the rankings on the productivity measure along with those twenty departments ranked by the most recent American Council on Education Report (1970). A number of differences appear. First, as Somit and Tanenhaus have noted, reputations change slowly. Many of the departments rated highly for 1969 were included in the 1957 report and as far back as $1925 .^{24}$ The index of productivity suggests that some of these continued high rankings may not be warranted, at least based on the criterion of journal productivity. This is not entirely surprising. Conceivably, many academics at distinguished institutions choose to devote their efforts at publication to the scholarly monograph or to textbook writing. If they do opt for a periodical outlet for their work, the favorite seems to be the APSR; note in Table 1 the few times Ivy League political scientists have published in the regional journals. On the other hand, when a department is "on the make" considerable pressure may be exerted on its faculty to publish as frequently as possible. This may lead to a concentration on regional journals where it is putatively easier to get published. At any rate, certain discrepancies between productivity as measured here and prestige rankings are obvious: MIT, for example, which is found in the top ten in the most

${ }^{22}$ Serious consideration was given to including the Social Science Quarterly in the productivity index since it is now officially recognized by the American Political Science Association as a regional journal (for the Southwest Political Science Association). A decision was finally made to omit this journal for three reasons: (1) it has only recently been accepted as an official regional political science journal (apparently in $1974)$; (2) it would probably not be regarded as in quite the same category as other strictly political science journals since it is interdisciplinary in nature; and (3) most of its articles are domestic in orientation which would further accentuate a potential American politics bias that may exist for the index as it now stands. It might also be mentioned here that $S S Q$ ranks ahead of both Polity and $W P Q$ in the Giles and Wright survey.

${ }^{23}$ Consideration was also given to presenting a productivity score that takes into account departmental size. This was rejected since most other attempts to evaluate departments are not concerned with output per faculty member, only the overall departmental stature. This is our only real concern as well. Later in the analysis a measure of size of department is included along with other characteristics in an attempt to account for variation in overall productivity scores.

24 Albert Somit and Joseph Tanenhaus, The Development of American Political Science: From Burgess to Behavioralism (Boston: Allyn and Bacon, 1967), pp. 162-65. 
TABle 1. Rankings and Weighted Productivity Scores of Amerigan Political Scienge Departments, 1964-1973

\begin{tabular}{|c|c|c|c|c|c|c|c|}
\hline \multirow[b]{2}{*}{$\operatorname{Rank}$} & \multirow[b]{2}{*}{ Department } & \multicolumn{5}{|c|}{ Number of Articles } & \multirow{2}{*}{$\begin{array}{c}\text { Weighted } \\
\text { Total }\end{array}$} \\
\hline & & $A P S R$ & JOP & AJPS & $W P Q$ & Polity & \\
\hline 1 & Wisconsin-Mad. & 28.00 & 10.00 & 10.50 & 5.00 & 2.00 & 53.30 \\
\hline 2 & Michigan .............................. & 25.33 & 9.50 & 12.00 & 3.00 & 0.00 & 48.23 \\
\hline 3 & Kentucky & 3.00 & 10.00 & 15.50 & 2.00 & 6.00 & 33.91 \\
\hline 4 & Yale & 23.67 & 5.50 & 1.00 & 1.00 & 2.00 & 32.39 \\
\hline 5 & Calif.-Berkeley & 16.33 & 6.50 & 2.25 & 7.50 & 0.00 & 30.89 \\
\hline 6 & Georgia & 5.00 & 9.67 & 10.33 & 5.50 & 2.00 & 30.24 \\
\hline 7 & Chicago & 15.33 & 4.00 & 4.00 & 4.00 & 1.00 & 27.09 \\
\hline 8 & Stanford & 16.67 & 3.50 & 3.00 & 5.00 & 0.00 & 26.99 \\
\hline 9 & Florida State & 7.50 & 3.50 & 9.50 & 6.00 & 1.50 & 26.04 \\
\hline 10 & Iowa & 6.50 & 4.47 & 10.67 & 3.80 & 1.00 & 24.83 \\
\hline 11 & 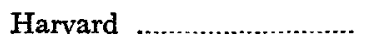 & 17.00 & 1.50 & 1.00 & 4.00 & 1.50 & 23.96 \\
\hline 12 & North Carolina .................. & 5.50 & 9.50 & 3.00 & 4.00 & 1.00 & 21.58 \\
\hline 13 & 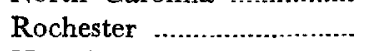 & 15.25 & 0.00 & 1.00 & 2.00 & 2.00 & 19.54 \\
\hline 14 & Hawaii & 9.00 & 3.00 & 0.00 & 7.00 & 2.00 & 19.36 \\
\hline 15 & Michigan State & 7.50 & 3.00 & 6.50 & 2.00 & 0.67 & 18.72 \\
\hline 16 & UCLA & 5.50 & 3.50 & 2.00 & 6.50 & 1.00 & 16.97 \\
\hline 17 & Ohio State & 8.25 & 2.50 & 6.00 & 0.00 & 0.50 & 16.72 \\
\hline 18 & 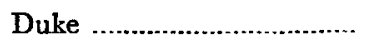 & 2.50 & 8.50 & 1.00 & 3.00 & 3.00 & 16.59 \\
\hline 19 & Syracuse ............................... & 3.50 & 6.50 & 2.00 & 6.00 & 0.00 & 16.58 \\
\hline 20.5 & Purdue & 2.50 & 3.00 & 3.00 & 7.00 & 2.00 & 15.69 \\
\hline 20.5 & Vanderbilt & 2.00 & 8.00 & 2.00 & 5.00 & 0.00 & 15.69 \\
\hline 22 & Texas & 1.50 & 10.50 & 1.50 & 3.00 & 0.00 & 15.45 \\
\hline 23 & Washington (StL) .......... & 6.50 & 4.50 & 4.00 & 0.00 & 0.00 & 14.58 \\
\hline 24 & 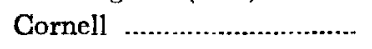 & 6.50 & 2.00 & 5.00 & 0.50 & 1.00 & 14.38 \\
\hline 25 & Arizona & 2.00 & 3.00 & 1.50 & 9.00 & 0.00 & 13.74 \\
\hline 26 & Wisconsin-Milw. ................ & 0.50 & 5.33 & 3.33 & 5.00 & 0.00 & 12.88 \\
\hline 27 & Indiana & 5.00 & 3.00 & 3.33 & 1.00 & 1.00 & 12.68 \\
\hline 28 & Massachusetts & 1.00 & 2.00 & 1.00 & 5.00 & 5.50 & 12.63 \\
\hline 29 & Rutgers & 1.00 & 8.00 & 2.00 & 2.00 & 0.00 & 12.21 \\
\hline 30 & 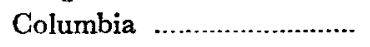 & 6.00 & 2.00 & 1.00 & 4.00 & 0.00 & 12.17 \\
\hline 31 & Calif.-Riverside ................... & 1.50 & 3.00 & 0.00 & 5.00 & 4.00 & 11.88 \\
\hline 32 & Northwestern & 2.00 & 1.80 & 5.50 & 2.00 & 1.00 & 11.41 \\
\hline 33 & Maryland ............................ & 4.50 & 3.50 & 0.00 & 3.00 & 1.00 & 11.18 \\
\hline 34 & Princeton & 8.67 & 1.00 & 0.50 & 1.00 & 0.00 & 10.93 \\
\hline 35 & Minnesota & 4.50 & 2.00 & 3.00 & 2.00 & 0.00 & 10.90 \\
\hline 36 & 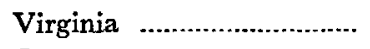 & 2.50 & 6.50 & 0.50 & 1.00 & 1.00 & 10.86 \\
\hline 37 & Oregon & 2.50 & 4.00 & 1.00 & 4.00 & 0.00 & 10.59 \\
\hline 38 & Wayne State .......................... & 3.00 & 1.00 & 4.00 & 1.50 & 1.00 & 9.81 \\
\hline 39 & Connecticut & 3.00 & 1.50 & 1.50 & 3.00 & 1.50 & 9.60 \\
\hline 40 & 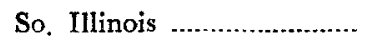 & 2.00 & 3.00 & 1.50 & 4.00 & 0.00 & 9.60 \\
\hline 41 & 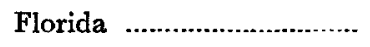 & 2.00 & 5.67 & 0.50 & 1.00 & 1.00 & 9.57 \\
\hline 42 & SUNY-Stony Brook ............ & 4.00 & 2.00 & 2.00 & 2.00 & 0.00 & 9.46 \\
\hline 43 & Emory & 0.00 & 4.50 & 3.50 & 1.00 & 1.00 & 9.28 \\
\hline 44.5 & Washington (Seattle) .... & 1.00 & 0.00 & 2.00 & 6.50 & 1.00 & 9.12 \\
\hline 44.5 & Johns Hopkins ....................... & 6.50 & 1.00 & 0.00 & 2.00 & 0.00 & 9.12 \\
\hline 46 & Calif,-Davis & 4.00 & 0.00 & 0.00 & 6.00 & 0.00 & 8.97 \\
\hline 47 & SUNY-Buffalo ................... & 0.50 & 5.00 & 3.00 & 0.00 & 1.00 & 8.95 \\
\hline 48 & Tulane & 2.00 & 4.00 & 2.33 & 0.00 & 1.00 & 8.84 \\
\hline 49 & Wesleyan & 4.25 & 3.00 & 0.00 & 1.00 & 1.00 & 8.79 \\
\hline 50 & Calif.-Santa Barbara ........ & 1.00 & 1.00 & 1.00 & 5.00 & 1.00 & 7.88 \\
\hline
\end{tabular}


recent $\mathrm{ACE}$ evaluation, does not appear among the fifty most productive departments. Likewise, the University of Illinois, which is one of the top twenty prestige departments, is not on the productivity list. Conversely, the most underrated departments, by journal productivity standards, would seem to be Kentucky, Georgia, Florida State, Hawaii, Michigan State, Ohio State, Duke, and Syracuse. Perhaps coincidently, four of these eight schools are located in the South.

TABLE 2. Comparison of Journal Productivity Ranking with Ranking by American Gouncrl on Education for American Political Science Departments*

\begin{tabular}{llll}
\hline & Productivity (1964-1973) & & ACE (1970) \\
\hline 1 & Wisconsin-Madison & 1 & Yale \\
2 & Michigan & 2 & Harvard \\
3 & Kentucky & 3 & Calif.-Berkeley \\
4 & Yale & 4 & Chicago \\
5 & Calif.-Berkeley & 5 & Michigan \\
6 & Georgia & 6.5 & MIT \\
7 & Chicago & 6.5 & Stanford \\
8 & Stanford & 8 & Wisconsin \\
9 & Florida State & 9 & Princeton \\
10 & Iowa & 10 & North Carolina \\
11 & Harvard & 11 & Columbia \\
12 & North Carolina & 12.5 & UCLA \\
13 & Rochester & 12.5 & Minnesota \\
14 & Hazaii & 15.5 & Cornell \\
15 & Michigan State & 15.5 & Indiana \\
16 & UCLA & 15.5 & Northwestern \\
17 & Ohio State & 15.5 & Rochester \\
18 & Duke & 18.5 & Iowa \\
19 & Syracuse & 18.5 & Oregon \\
20.5 & Purdue & 21 & Illinois \\
20.5 & Vanderbilt & 21 & Johns Hopkins \\
& & 21 & Washington (StL) \\
\hline \hline
\end{tabular}

* The italicized universities do not appear in both rankings.

A further word seems necessary at this point concerning the potential bias of the productivity index toward American politics. Apparently several of the departments that do less well on this measure than might be expected, e.g., Princeton, Columbia, Cornell, and MIT, are especially recognized for their strengths in comparative and international politics. ${ }^{25}$ An analysis of World Politics (first on the journal rankings) and Comparative Politics (tied for seventh with AJPS) would likely reveal that faculty from these schools are indeed prolific. These specialists might well consider these journals as preferable publication outlets to any of the regional journals except perhaps JOP. Another related consideration is the association of certain distinguished institutions with the sponsorship of particular journals that might cause their faculty to seek publication there rather than in a regional periodical, e.g., Columbia's association with Political Science Quarterly, Princeton with World Politics, the Annals at Pennsylvania, and Public Policy at Harvard. Several of these same places also have prominent university presses which might provide an additional inducement to such faculties to deemphasize the journals and to concentrate on book publication. All of this is to indicate that we do not question the right of certain schools to be thought of as leaders in the discipline. Our productivity measure simply indicates that some of these institutions have achieved

${ }^{20}$ This observation was shared with us by Professor Larry B. Hill. 
their enviable position by stressing other forms of scholarly activity than the publication of articles in general purpose journals.

\section{Accounting for Journal Productivity}

A number of intangible factors undoubtedly play an important part in determining why one political science department has higher productivity levels than another. An individual faculty member's incentive as well as his or her capacity to undertake publishable research surely is predominantly the result of personal traits, level of motivation, research training, and even luck. At the same time, departments that manifest high levels of output may have certain things in common so that it might be possible to identify specific departmental or even university characteristics that are associated with variation in productivity levels. At this preliminary stage it seems inappropriate, partly because of data limitations, to ponder these questions in rigorous theoretical terms. Yet certain information is available that permits us to do more than speculate about these relationships. In particular, several measures can be found that seem to reflect the resource base available to support research activities within departments of political science. It would seem logical that those departments that have more faculty, higher rates of pay, and access to research-related facilities might have an advantage over their less fortunate counterparts within the discipline. To the extent that productivity is determined by more than individual qualities, perhaps institutional resources and incentives have an impact upon journal output. Using certain selected features of both departments and institutions, simple, partial, and multiple correlation techniques were chosen to test this basic assumption. The results are found in Table 3.

Table 3. Coefficients of Simple, Partad, and Multiple Correlation Between Productivity Index and Selegted Measures of Institutronal Resources

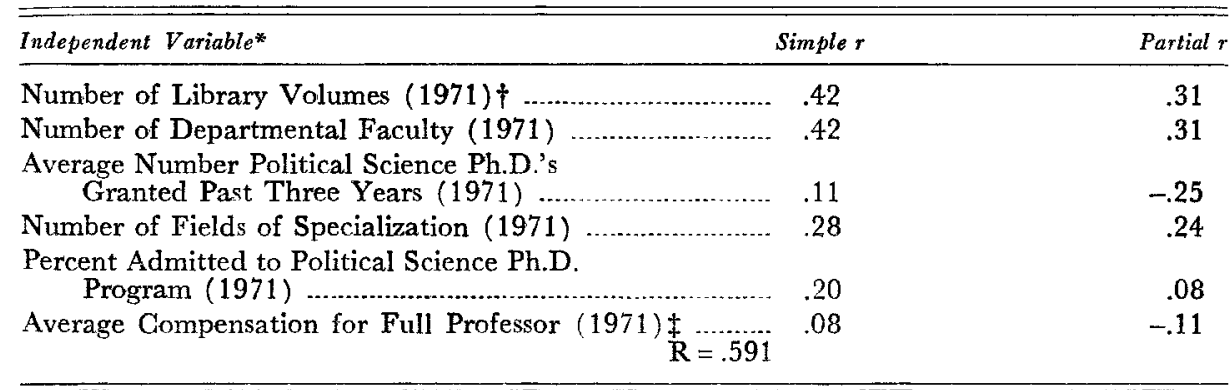

* Unless otherwise noted, source is A Guide to Graduate Study in Political Science (Washington, D.C.: American Political Science Association, 1972).

$\uparrow$ National Center for Educational Statistics, Library Statistics of Colleges and Universities: Institutional Data, Part A, Fall, 1971 (Washington, D.C.: Government Printing Office, 1972), pp. 6-51.

\$AAUP Bulletin 57 (Summer 1971): 248-85.

Not unexpectedly, the overall degree of association between the six independent variables and the index of productivity is not exceptionally strong $(R=.591)$. When partial coefficients are examined, two measures - number of library volumes and size of departmental faculty - remain of considerable importance (each with a partial .31). The number of fields of specialization within a department remains the next most important positive effect (partial $r=.24$ ). Two of the other three independent variables reflect a negative sign when partialling occurs suggesting that they not only make no contribution to increased levels of productivity but actually help depress that result. Of special note is the singular lack of effect of professorial salaries on research output. Thus, while considerable variation remains unexplained, it does appear that larger, specialized departments, supported by extensive 
library holdings, are more likely than others to demonstrate higher levels of published scholarship.

\section{Conctusion}

The elusive nature of scientific productivity invites legitimate disputes over the most appropriate method of measuring this important phenomenon. Yet discussions concerning the state or progress of a discipline, or arguments over where contributions are being made, must proceed with less specificity than would otherwise be desirable without some effort at quantifying significant aspects of an academic discipline.

In this brief report we first considered some of the attempts to assess scientific productivity generally before developing a particular measure of scholarly output for application to departments of political science. The index developed was based on publications in the American Political Science Review and the four regional journals for the period 1964-73. The top fifty departments were presented and compared with the qualitative ratings provided in the most recent ACE report. Although certain interesting differences were noted, it was not expected that a quantitative output index would necessarily correspond closely with prestige ratings. This does not mean, however, that both are not needed, only that they do not reflect quite the same departmental attributes. It was also discovered that productivity scores were modestly associated with certain departmental and institutional characteristics.

No claim is offered here that an index of journal productivity is the definitive quantitative measure of scholarly achievement even if one prefers something of this sort over the subjective rankings. We do hope, however, that the present effort will serve to stimulate further interest and research among political scientists concerning the nature of scientific productivity. We believe, as well, that such quantitative output measures do have certain desirable qualities that make them intrinsically interesting and useful. 